\title{
Gestational weight gain charts for different body mass index groups for women in Europe, North America, and Oceania
}

Susana Santos ${ }^{1,2}$, Iris Eekhout ${ }^{3,4}$, Ellis Voerman ${ }^{1,2}$, Romy Gaillard ${ }^{1,2}$, Henrique Barros ${ }^{5,6}$, Marie-Aline Charles ${ }^{7,8}$, Leda Chatzi ${ }^{9,10,11}$, Cécile Chevrier ${ }^{12}$, George P. Chrousos ${ }^{13}$, Eva Corpeleijn ${ }^{14}$, Nathalie Costet ${ }^{12}$, Sarah Crozier ${ }^{15}$, Myriam Doyon ${ }^{16}$, Merete Eggesb $\varnothing^{17}$, Maria Pia Fantini ${ }^{18}$, Sara Farchi ${ }^{19}$, Francesco Forastiere ${ }^{19}$, Luigi Gagliardi ${ }^{20}$, Vagelis Georgiu ${ }^{10}$, Keith M. Godfrey ${ }^{15,21}$, Davide Gori ${ }^{18}$, Veit Grote ${ }^{22}$, Wojciech Hanke ${ }^{23}$, Irva Hertz-Picciotto ${ }^{24}$, Barbara Heude ${ }^{7,8}$, Marie-France Hivert ${ }^{16,25,26}$, Daniel Hryhorczuk ${ }^{27}$, Rae-Chi Huang ${ }^{28}$, Hazel Inskip ${ }^{15,21}$, Todd A. Jusko ${ }^{29}$, Anne M. Karvonen ${ }^{30}$, Berthold Koletzko ${ }^{22}$, Leanne K. Küpers ${ }^{14,31,32}$, Hanna Lagström ${ }^{33}$, Debbie A. Lawlor ${ }^{31,32}$, Irina Lehmann ${ }^{34}$, Maria-Jose Lopez-Espinosa ${ }^{35,36}$, Per Magnus ${ }^{37}$, Renata Majewska ${ }^{38}$, Johanna Mäkelä ${ }^{39}$, Yannis Manios ${ }^{40}$, Sheila W. McDonald ${ }^{41}$, Monique Mommers ${ }^{42}$, Camilla S. Morgen ${ }^{43,44}$, George Moschonis ${ }^{45}$, L'ubica Murínováa ${ }^{46}$, John Newnham ${ }^{47}$, Ellen A. Nohr ${ }^{48}$, Anne-Marie Nybo Andersen ${ }^{44}$, Emily Oken ${ }^{25}$, Adriëtte J. J. M. Oostvogels ${ }^{49}$, Agnieszka Pac ${ }^{38}$, Eleni Papadopoulou ${ }^{50}$, Juha Pekkanen ${ }^{30,51}$, Costanza Pizzi ${ }^{52}$, Kinga Polanska ${ }^{23}$, Daniela Porta ${ }^{19}$, Lorenzo Richiardi ${ }^{52}$, Sheryl L. Rifas-Shiman ${ }^{25}$, Nel Roeleveld ${ }^{53}$, Loreto Santa-Marina ${ }^{36,54,55}$, Ana C. Santos ${ }^{5,6}$, Henriette A. Smit ${ }^{56}$, Thorkild I. A. Sørensen ${ }^{44,57}$, Marie Standl ${ }^{58}$, Maggie Stanislawski ${ }^{59}$, Camilla Stoltenberg ${ }^{60,61}$, Elisabeth Thiering ${ }^{58,62}$, Carel Thijs ${ }^{42}$, Maties Torrent ${ }^{63}$, Suzanne C. Tough ${ }^{41,64}$, Tomas Trnovec ${ }^{65}$, Marleen M. H. J. van Gelder ${ }^{53,66}$, Lenie van Rossem ${ }^{56}$, Andrea von Berg ${ }^{67}$, Martine Vrijheid ${ }^{36,68,69}$, Tanja G. M. Vrijkotte ${ }^{49}$, Oleksandr Zvinchuk ${ }^{70}$, Stef van Buuren ${ }^{3,71}$ and Vincent W. V. Jaddoe ${ }^{1,2,72^{*}}$

\footnotetext{
Abstract

Background: Gestational weight gain differs according to pre-pregnancy body mass index and is related to the risks of adverse maternal and child health outcomes. Gestational weight gain charts for women in different prepregnancy body mass index groups enable identification of women and offspring at risk for adverse health outcomes. We aimed to construct gestational weight gain reference charts for underweight, normal weight, overweight, and grades 1, 2 and 3 obese women and to compare these charts with those obtained in women with uncomplicated term pregnancies.

(Continued on next page)
}

\footnotetext{
* Correspondence: v.jaddoe@erasmusmc.nl

${ }^{1}$ The Generation R Study Group, Erasmus MC, University Medical Center

Rotterdam, PO Box 2040, 3000 CA Rotterdam, the Netherlands

2Department of Pediatrics, Sophia Children's Hospital, Erasmus MC, University

Medical Center Rotterdam, Rotterdam, the Netherlands

Full list of author information is available at the end of the article
}

(c) The Author(s). 2018 Open Access This article is distributed under the terms of the Creative Commons Attribution 4.0 International License (http://creativecommons.org/licenses/by/4.0/), which permits unrestricted use, distribution, and reproduction in any medium, provided you give appropriate credit to the original author(s) and the source, provide a link to the Creative Commons license, and indicate if changes were made. The Creative Commons Public Domain Dedication waiver (http://creativecommons.org/publicdomain/zero/1.0/) applies to the data made available in this article, unless otherwise stated. 
(Continued from previous page)

Methods: We used individual participant data from 218,216 pregnant women participating in 33 cohorts from Europe, North America, and Oceania. Of these women, 9065 (4.2\%), 148,697 (68.1\%), 42,678 (19.6\%), 13,084 (6.0\%), 3597 (1.6\%), and 1095 (0.5\%) were underweight, normal weight, overweight, and grades 1, 2, and 3 obese women, respectively. A total of 138, 517 women from 26 cohorts had pregnancies with no hypertensive or diabetic disorders and with term deliveries of appropriate for gestational age at birth infants. Gestational weight gain charts for underweight, normal weight, overweight, and grade 1, 2, and 3 obese women were derived by the Box-Cox $t$ method using the generalized additive model for location, scale, and shape.

Results: We observed that gestational weight gain strongly differed per maternal pre-pregnancy body mass index group. The median (interquartile range) gestational weight gain at 40 weeks was $14.2 \mathrm{~kg}$ (11.4-17.4) for underweight women, $14.5 \mathrm{~kg}(11.5-17.7)$ for normal weight women, $13.9 \mathrm{~kg}(10.1-17.9)$ for overweight women, and $11.2 \mathrm{~kg}$ (7.0-15.7), $8.7 \mathrm{~kg}(4.3-13.4)$ and $6.3 \mathrm{~kg}(1.9-11.1)$ for grades 1, 2, and 3 obese women, respectively. The rate of weight gain was lower in the first half than in the second half of pregnancy. No differences in the patterns of weight gain were observed between cohorts or countries. Similar weight gain patterns were observed in mothers without pregnancy complications.

Conclusions: Gestational weight gain patterns are strongly related to pre-pregnancy body mass index. The derived charts can be used to assess gestational weight gain in etiological research and as a monitoring tool for weight gain during pregnancy in clinical practice.

Keywords: Weight gain, Pregnancy, Charts, References

\section{Background}

Gestational weight gain is an important predictor of adverse maternal and child health outcomes [1]. Insufficient weight gain is associated with increased risks of preterm birth and delivering a low birth weight infant, whereas excessive weight gain is associated with increased risks of gestational hypertension, preterm birth, delivering a high birth weight infant, cesarean delivery, and childhood overweight [2-5].

Appropriate gestational weight gain charts are necessary to monitor the progress of weight gain and to enable risk selection. Gestational weight gain charts have been derived from country-specific studies that varied in sample selection, study design, and methods of data collection and statistical analysis [6]. A study of the INTERGROWTH-21st Project among 3097 normal weight women from Brazil, China, India, Italy, Kenya, Oman, UK, and USA described the patterns in maternal gestational weight gain from 14 weeks onwards in healthy pregnancies with good maternal and perinatal outcomes [7]. Another previous hospital-based study developed gestational weight gain charts for 4246 overweight and obese US women, respectively, delivering uncomplicated term pregnancies [8]. Also, weight gain for gestational age charts for underweight, normal weight, overweight, and grades 1, 2, and 3 obese women were created in a large population-based cohort of 141,767 Swedish women with term, non-anomalous, singleton pregnancies and no pre-existing hypertension or diabetes [9]. Results from these studies showed the strong influence of pre-pregnancy body mass index (BMI) on gestational weight gain. The generalizability of these charts to other populations is not known. International gestational weight gain charts for specific pre-pregnancy BMI groups are important to improve clinical monitoring and risk selection of pregnant women.

We used individual participant data from 218,216 pregnant women from 33 European, North American, and Oceania pregnancy cohort studies to assess the pattern of weight gain and to construct gestational weight gain charts for underweight, normal weight, overweight, and grades 1, 2, and 3 obese women. Additionally, we compared these charts to those obtained in 138,517 pregnant women from 26 cohorts who had uncomplicated term pregnancies.

\section{Methods \\ Inclusion criteria and participating cohorts}

This study was embedded in an international collaboration on Maternal Obesity and Childhood Outcomes (MOCO). Pregnancy and birth cohort studies participated if they included mothers with singleton live-born children born from 1989 onwards, had information available on maternal pre/early-pregnancy BMI and at least one offspring measurement (birth weight or childhood BMI) and were approved by their local institutional review boards. We identified 50 cohorts from Europe, North America, and Oceania selected from the existing collaborations on childhood health (EarlyNutrition Project, CHICOS Project, www.birthcohorts.net assessed until July 2014). We invited these cohorts, of which 39 cohorts agreed to participate, providing data of 239,621 singleton births. Detailed information on these cohorts 
can be found in www.birthcohorts.net. We included cohorts with information on pre-pregnancy BMI and weight measurements throughout pregnancy with information on the corresponding gestational age (33 cohorts). Per cohort, women were included if they had pre-pregnancy BMI to allow classification into the specific pre-pregnancy BMI groups. Therefore, all women had information on weight at 0 weeks, which refers to pre-pregnancy weight. Since the data were modeled cross-sectionally, no further restriction was applied regarding the weight measurements throughout pregnancy. Our final sample comprised 33 cohorts and 218,216 women who contributed with 679,262 gestational weight measurements, of which 218,216 at 0 weeks and 461,046 throughout pregnancy. Of these women, 9065 (4.2\%), 148,697 (68.1\%), 42,678 (19.6\%), 13,084 (6.0\%), 3597 (1.6\%), and 1095 (0.5\%) were underweight, normal weight, overweight, obese grade 1 , obese grade 2 , and obese grade 3 , respectively (flow chart is given in Additional file 1: Figure S1). Twenty-seven of the 33 cohorts defined themselves as regionally or nationally based studies, four as hospital-based (Co.N.ER, EDEN, GASPII, LUKAS), one as internet users-based (NINFEA), and one as studying selected populations (FCOU). To also obtain the charts in uncomplicated pregnancies, we further restricted our sample to women who had pregnancies with no hypertensive or diabetic disorders and with term deliveries of appropriate for gestational age at birth infants. This sample of uncomplicated term pregnancies comprised 26 cohorts and 138, 517 women, of which $5541,97,263,26,320,7160,1752$, and 481 were underweight, normal weight, overweight, and obese grades 1, 2 and 3, respectively. Anonymized datasets were stored on a single central secured data server with access for the main analysts (SS, IE).

\section{Maternal anthropometrics}

Maternal anthropometrics were measured, derived from clinical records or self-reported (cohort-specific information is shown in Additional file 1: Table S1). Maternal pre-pregnancy BMI was calculated from information on height and weight before pregnancy and was categorized as underweight $\left(<18.5 \mathrm{~kg} / \mathrm{m}^{2}\right)$, normal weight (18.5$\left.24.9 \mathrm{~kg} / \mathrm{m}^{2}\right)$, overweight $\left(25.0-29.9 \mathrm{~kg} / \mathrm{m}^{2}\right)$, obesity grade $1\left(30.0-34.9 \mathrm{~kg} / \mathrm{m}^{2}\right)$, obesity grade $2\left(35.0-39.9 \mathrm{~kg} / \mathrm{m}^{2}\right)$, and obesity grade $3\left(\geq 40.0 \mathrm{~kg} / \mathrm{m}^{2}\right)$ according to the World Health Organization criteria [10]. Data were obtained on early, mid, and late pregnancy weight as the closest measurement to 13 weeks of gestation (range 619.9 weeks of gestation), the closest measurement to 26 weeks of gestation (range 20-31.9 weeks of gestation), and the closest measurement to 40 weeks of gestation (range 32-45 weeks of gestation). For the construction of the charts, we created, in a long data format, one single weight variable with the corresponding gestational age. Then, weight gain was calculated as the difference between the weight at certain gestational age and the pre-pregnancy weight. Cohort-specific information on the methods used to estimate gestational age is shown in Additional file 1: Table S1.

\section{Statistical analysis}

We modeled gestational weight gain by gestational age separately for each maternal pre-pregnancy BMI group to develop the pre-pregnancy BMI group-specific gestational weight gain charts. We had available weight measurements at the start of pregnancy and subsequent weights from 8 weeks onwards. For that reason, we modeled from the week 0 onwards. We initially fitted the model in which each woman had a weight gain of $0 \mathrm{~kg}$ at the start of pregnancy (0 weeks), but the lack of variation in the outcome caused severe numerical problems. To address this, we imagined a nudge effect equal to the measurement error of body weight. It is known that measurement error of a single dial measurement is about $0.70 \mathrm{~kg}$ [11], so the variance of the gain score is equal to $0.70^{2}+0.70^{2}=0.98 \mathrm{~kg}$. For each woman, the weight gain at the start of pregnancy was taken as a random draw from the Gaussian distribution with mean of 0 and variance of $0.98 \mathrm{~kg}$. The size of the measurement error was used since it is theoretically based but any variance could have been applied. We started the modeling using a Box-Cox Cole and Green distribution (Box-Cox normal), which turned out to be too strict to fit the data. Therefore, we fitted the models, separately for each maternal pre-pregnancy BMI group, by the Box-Cox $t$ (BCT) method using the generalized additive model for location, scale, and shape (GAMLSS) package in R version 3.3.1 [12]. We used GAMLSS instead of quantile regression since in the latter the centiles are estimated individually and thus may cross, leading to an invalid distribution for the outcome. Additionally, there are no distributional assumptions in quantile regression, which may hamper the estimation of the outer centiles with sufficient precision even when there is enough information at the tails [13]. In the BCT method, the default links from the GAMLSS package, namely, an identity link for the mu and nu parts and a log link for the sigma and tau parts of the model, were used. The BCT method summarizes the distribution in four time-dependent smooth curves representing the median (M-curve), the variation (S-curve), the skewness (L-curve), and the kurtosis (T-curve) [14]. The smoothing family and the amount of smoothing were determined by visual inspection of the worm plots, the fitted centiles, and the $Q$ statistics $[15,16]$. The worm plots describe salient features of the time-conditional $z$ score distribution and aid in finding proper smoothing values for the model [15].The 
M-curve of the models for weight gain was fitted using B-splines smoothing on gestational age with specified internal breakpoints to define the splines and three degrees which is similar to a cubic spline. Cubic splines smoothing on gestational age was also used for the $\mathrm{S}$-curve, L-curve, and T-curve. The models for the different maternal pre-pregnancy BMI groups were fitted with different internal breakpoints and degrees of freedom for the curves. Model specifications for each BMI group are given in Additional file 1: Table S2. Data were modeled cross-sectionally since taking the correlation between repeated observations of the same individual into account seems to have negligible effects on the location and precision of the centiles [13]. We tested for pre-pregnancy weight as well as cohort and country differences in the models. To confirm that using a more advanced model was justified, we tested for each maternal pre-pregnancy BMI group whether our model had a better fit as compared to a simple linear model using the Bayesian information criterion. We also compared our charts to those obtained, using the same analytical strategy and models, in a sample restricted to women who had uncomplicated term pregnancies.

\section{Results}

\section{Subject characteristics}

Characteristics of the participating pregnancy cohorts are given in Table 1. Overall, the median maternal pre-pregnancy BMI and total gestational weight gain were $22.7 \mathrm{~kg} / \mathrm{m}^{2}$ (interquartile range $20.8-25.4 \mathrm{~kg} / \mathrm{m}^{2}$ ) and $14.0 \mathrm{~kg}$ (interquartile range 11.0-17.9 kg), respectively. The number of weight measurements during pregnancy available per participating cohort and per maternal pre-pregnancy BMI group is given in Additional file 1: Table S3. The overall sample size according to gestational age for each maternal pre-pregnancy BMI group is shown in Additional file 1: Figure S2. For the construction of the charts, most weight measurements were available around 15,30 , and 40 weeks of gestation and for normal weight and overweight women.

\section{Gestational weight gain charts}

Figure 1 shows selected percentiles of weight gain for gestational age (P2.3 (- 2 SD), P16 (- 1 SD), P50 (0 SD), P84 (1 SD), and P97.7 (2 SD)) for underweight, normal weight, overweight, and grades 1, 2, and 3 obese women. Gestational weight gain strongly differed per maternal pre-pregnancy BMI group and was gradually lower across higher BMI groups. The median (interquartile range) gestational weight gain at 40 weeks was $14.2 \mathrm{~kg}$ (11.4-17.4) for underweight women; $14.5 \mathrm{~kg}$ (11.5-17.7) for normal weight women; $13.9 \mathrm{~kg}(10.1-17.9)$ for overweight women; and $11.2 \mathrm{~kg}$ (7.0-15.7), $8.7 \mathrm{~kg}(4.3-13.4)$, and $6.3 \mathrm{~kg}(1.9-11.1)$ for grades 1, 2, and 3 obese women, respectively. For all maternal pre-pregnancy BMI groups, weight gain trajectories throughout pregnancy followed a non-linear shape. The Bayesian information criterion supported our non-linear model that showed a better statistical fit as compared to a simple linear model. The rate of weight gain was lower in the first half than in the second half of pregnancy for all pre-pregnancy BMI groups. Especially in overweight women, we observed a higher rate of weight gain around 22-25 weeks of gestation. The coefficients of variation between pre-pregnancy weights within the same BMI group, and between cohorts and countries were smaller than the measurement error (variance of the weight gain of $0.98 \mathrm{~kg}$ ), reinforcing the similarities in the charts for the variety of weights within each BMI group and among cohorts and countries. These findings also suggest no strong cohort birth period or region effects on our charts. The predicted $z$ scores for the average weight gain according to gestational age for each maternal BMI group are shown in Additional file 1: Figure S3. Only a small misfit, caused by less data available, was observed for grade 3 obese women. Estimates of weight gain for selected percentiles according to gestational age and maternal BMI groups are given in Additional file 1: Tables S4-S9. Figure 2 shows the equation for the calculation of $z$ scores based on a BCT model. The parameters of our $\mathrm{BCT}$ model at a certain gestational age to allow the calculation of $z$ scores are given in Additional file 1: Tables S4-S9 (available in an excel spreadsheet upon request). An online tool to produce individual $z$ scores and percentiles for gestational weight gain in singleton pregnancies based on our international reference charts is available at https://lifecycle-project.eu.

Similar charts were obtained when we applied the same models to a sample without pregnancy complications (Fig. 3). We also observed similar estimates of weight gain for P50 at 20 and 40 weeks of gestation for all maternal pre-pregnancy BMI groups in all pregnant women and in women without any pregnancy complication. Although the estimates were largely similar, we observed that women without any pregnancy complication who were underweight or normal weight tended to gain higher weight and those who were overweight or obese tended to gain lower weight, compared to the full group of pregnant women (Table 2). Similar results were observed when restricting all analyses to the regionally and nationally based cohorts (data not shown).

\section{Discussion}

In this study, we developed gestational weight gain charts for different pre-pregnancy BMI groups for women in Europe, North America, and Oceania. Gestational weight gain strongly differed per maternal pre-pregnancy BMI group and was gradually lower across higher BMI groups. For all maternal BMI groups, weight gain throughout 
Table 1 Characteristics of the participating pregnancy cohorts $(n=218,216)^{\text {a }}$

\begin{tabular}{|c|c|c|c|}
\hline $\begin{array}{l}\text { Cohort name, number of participants, birth years } \\
\text { (country) }\end{array}$ & $\begin{array}{l}\text { Maternal pre-pregnancy body mass index } \\
\left(\mathrm{kg} / \mathrm{m}^{2}\right)\end{array}$ & $\begin{array}{l}\text { Maternal total gestational weight gain } \\
(\mathrm{kg})\end{array}$ & $\begin{array}{l}\text { Gestational age at birth } \\
\text { (weeks) }\end{array}$ \\
\hline $\begin{array}{l}\text { ABCD, } n=7820,2003-2004 \\
\text { (The Netherlands) }\end{array}$ & $22.3(20.5,24.8)$ & NA & $40.0(39.0,41.0)$ \\
\hline $\begin{array}{l}\text { ALSPAC, } n=11,344,1991-1992 \\
(\text { UK) }\end{array}$ & $22.2(20.5,24.4)$ & $12.5(9.5,15.5)$ & $40.0(39.0,41.0)$ \\
\hline $\begin{array}{l}\text { AOB/F, } n=2941,2008-2010 \\
\text { (Canada) }\end{array}$ & $23.0(20.8,26.3)$ & NA & $39.0(38.0,40.0)$ \\
\hline $\begin{array}{l}\text { Co.N.ER, } n=637,2004-2005 \\
\text { (Italy) }\end{array}$ & $21.1(19.7,23.4)$ & $13.0(10.0,16.0)$ & $39.0(39.0,40.0)$ \\
\hline $\begin{array}{l}\text { DNBC, } n=42,761,1996-2002 \\
(\text { Denmark) }\end{array}$ & $22.5(20.7,25.1)$ & $15.0(12.0,18.0)$ & $40.1(39.1,41.0)$ \\
\hline $\begin{array}{l}\text { EDEN, } n=1875,2003-2005 \\
\text { (France) }\end{array}$ & $22.1(20.1,25.3)$ & $13.0(11.0,16.3)$ & $39.0(39.0,40.0)$ \\
\hline $\begin{array}{l}\text { FCOU, } n=3650,1993-1996 \\
\text { (Ukraine) }\end{array}$ & $21.6(19.8,24.0)$ & $12.0(9.2,15.0)$ & $40.0(39.0,41.0)$ \\
\hline $\begin{array}{l}\text { GASPII, } n=675,2003-2004 \\
\text { (Italy) }\end{array}$ & $21.3(19.8,23.6)$ & $13.0(10.5,16.0)$ & $40.0(39.0,41.0)$ \\
\hline $\begin{array}{l}\text { GECKO Drenthe, } n=2501,2006-2007 \text { (The } \\
\text { Netherlands) }\end{array}$ & $23.7(21.5,26.8)$ & $13.0(10.0,17.0)$ & $40.0(39.0,40.9)$ \\
\hline Generation R, $n=71832002-2006$ (The Netherlands) & $22.6(20.8,25.4)$ & $12.0(9.0,16.0)$ & $40.1(39.0,41.0)$ \\
\hline Generation XXI, n=7621, 2005-2006 (Portugal) & $22.9(21.0,25.8)$ & $13.0(10.0,17.0)$ & $39.0(38.0,40.0)$ \\
\hline $\begin{array}{l}\text { GENESIS, } n=2218,2003-2004 \\
\text { (Greece) }\end{array}$ & $21.9(20.2,24.0)$ & $13.0(10.0,17.0)$ & $40.0(39.0,40.0)$ \\
\hline $\begin{array}{l}\text { Gen3G, } n=846,2010-2013 \\
\text { (Canada) }\end{array}$ & $23.3(20.9,27.3)$ & $13.7(10.7,17.0)$ & $39.4(38.5,40.2)$ \\
\hline $\begin{array}{l}\text { GINIplus, } n=2329,1995-1998 \\
\text { (Germany) }\end{array}$ & $22.1(20.4,24.2)$ & $13.0(10.0,15.7)$ & $40.0(39.0,41.0)$ \\
\hline $\begin{array}{l}\text { HUMIS, } n=1067,2003-2008 \\
\text { (Norway) }\end{array}$ & $23.5(21.3,26.2)$ & $14.0(11.0,18.0)$ & $40.1(39.0,41.1)$ \\
\hline $\begin{array}{l}\text { INMA, } n=2561,1997-2008 \\
\text { (Spain) }\end{array}$ & $22.5(20.7,25.0)$ & $13.5(10.5,16.6)$ & $39.9(38.9,40.6)$ \\
\hline $\begin{array}{l}\text { KOALA, } n=2812,2000-2002 \\
\text { (The Netherlands) }\end{array}$ & $22.7(20.9,25.3)$ & $14.0(11.0,17.0)$ & $40.0(39.0,40.0)$ \\
\hline $\begin{array}{l}\text { Krakow Cohort, } n=503 \text {, } \\
\text { 2000-2003 (Poland) }\end{array}$ & $21.0(19.5,22.7)$ & $15.0(12.0,18.0)$ & $40.0(39.0,40.0)$ \\
\hline $\begin{array}{l}\text { LISAplus, } n=2962,1997-1999 \\
\text { (Germany) }\end{array}$ & $21.7(20.2,24.1)$ & $14.0(11.5,17.0)$ & $40.0(39.0,41.0)$ \\
\hline $\begin{array}{l}\text { LUKAS, } n=417,2002-2005 \\
\text { (Finland) }\end{array}$ & $24.1(21.9,27.2)$ & $13.8(10.9,17.8)$ & $40.0(39.0,40.0)$ \\
\hline $\begin{array}{l}\text { MoBa, } n=88,503,1999-2009 \\
\text { (Norway) }\end{array}$ & $23.1(21.1,25.9)$ & $15.0(11.0,18.0)$ & $40.1(39.1,41.0)$ \\
\hline $\begin{array}{l}\text { NINFEA, } n=2237,2005-2010 \\
(\text { Italy })^{c}\end{array}$ & $21.4(19.9,23.9)$ & $12.0(10.0,15.0)$ & $39.7(38.9,40.7)$ \\
\hline $\begin{array}{l}\text { PÉLAGIE, } n=1490,2002-2005 \\
\text { (France) }\end{array}$ & $21.6(20.0,23.8)$ & NA & $40.0(39.0,40.0)$ \\
\hline $\begin{array}{l}\text { PIAMA, } n=3459,1996-1997 \\
\text { (The Netherlands) }\end{array}$ & $22.2(20.6,24.3)$ & $13.0(10.0,16.0)$ & $40.0(39.1,40.9)$ \\
\hline $\begin{array}{l}\text { Piccolipiù, } n=3294,2011-2015 \\
\text { (Italy) }\end{array}$ & $21.7(19.9,24.2)$ & $13.0(10.0,15.0)$ & $39.0(39.0,40.0)$ \\
\hline $\begin{array}{l}\text { PRIDE Study, } n=1513,2011-2015 \\
\text { (The Netherlands) }\end{array}$ & $22.5(20.7,24.8)$ & $14.0(11.0,17.0)$ & $39.0(39.0,40.0)$ \\
\hline $\begin{array}{l}\text { Project Viva, } n=2106, \\
1999-2002 \text { (United States) }\end{array}$ & $23.5(21.0,27.3)$ & $15.5(12.3,19.1)$ & $39.7(38.9,40.6)$ \\
\hline $\begin{array}{l}\text { Raine Study, } n=2791 \text {, } \\
\text { 1989-1992 (Australia) }\end{array}$ & $21.3(19.6,23.7)$ & NA & $39.0(38.0,40.0)$ \\
\hline $\begin{array}{l}\text { REPRO_PL, } n=1409, \\
\text { 2007-2011(Poland) }\end{array}$ & $21.5(19.8,23.8)$ & $12.0(9.0,15.0)$ & $39.0(38.5,40.0)$ \\
\hline RHEA, $n=816,2007-2008$ & $23.3(21.2,26.2)$ & $13.0(10.0,17.0)$ & $38.0(38.0,39.0)$ \\
\hline
\end{tabular}


Table 1 Characteristics of the participating pregnancy cohorts $(n=218,216)^{\mathrm{a}}$ (Continued)

\begin{tabular}{llll}
\hline $\begin{array}{l}\text { Cohort name, number of participants, birth years } \\
\text { (country) }\end{array}$ & $\begin{array}{l}\text { Maternal pre-pregnancy body mass index } \\
\left(\mathrm{kg} / \mathrm{m}^{2}\right)\end{array}$ & $\begin{array}{l}\text { Maternal total gestational weight gain } \\
(\mathrm{kg})\end{array}$ & $\begin{array}{l}\text { Gestational age at birth } \\
(\text { weeks })\end{array}$ \\
\hline $\begin{array}{l}\text { Slovak PCB study, } n=1048,2002-2004 \text { (Slovakia) } \\
\text { STEPS, } n=1708,2008-2010\end{array}$ & $21.2(19.5,24.0)$ & $13.0(10.0,17.0)$ & $40.0(39.0,40.0)$ \\
(Finland) & $23.0(21.1,26.1)$ & $13.9(10.8,17.4)$ & $40.0(39.0,41.0)$ \\
$\begin{array}{l}\text { SWS, } n=3119,1998-2007 \\
\text { (UK) }\end{array}$ & $24.1(21.9,27.4)$ & $11.9(8.3,15.7)$ & $40.0(39.0,41.0)$ \\
Total group & $22.7(20.8,25.4)$ & $14.0(11.0,17.9)$ & $40.0(39.0,41.0)$ \\
\hline
\end{tabular}

${ }^{a}$ Values are expressed as medians (interquartile range). NA not available

${ }^{b}$ Subset of participants with offspring body mass index available at 7 years by the time of data transfer (May 2015)

'Subset of participants with follow-up completed at 4 years of child's age by the time of data transfer (March 2015)

pregnancy followed a non-linear trajectory. The rate of weight gain was greater in the second than in the first half of pregnancy. No differences in the patterns of weight gain were observed between cohorts or countries. Our reference charts were largely similar to those obtained in a sample restricted to uncomplicated term pregnancies.

\section{Interpretation of main findings}

Gestational weight gain is an important predictor of adverse maternal and child health outcomes [1]. Weight gain reflects multiple components. It has been suggested that about $30 \%$ of gestational weight gain comprises the fetus, amniotic fluid, and placenta, whereas the

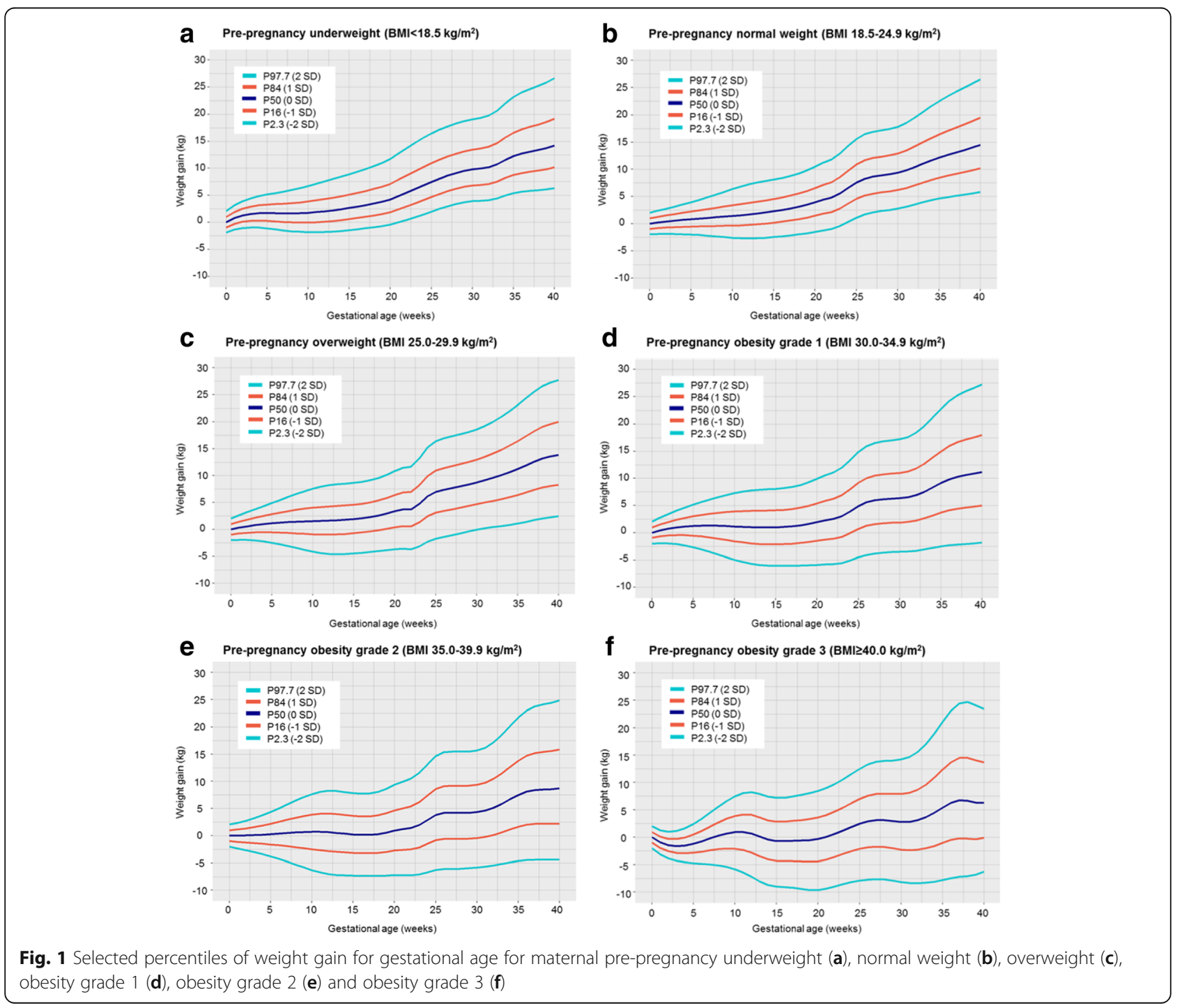




$$
\mathrm{Z}=\left\{\begin{array}{l}
\frac{1}{S * L}\left[\left(\frac{Y}{M}\right)^{L}-1\right], \text { if } L \neq 0 \\
\frac{1}{S} \log \left(\frac{Y}{M}\right), \text { if } L=0
\end{array}\right.
$$

Considering a normal weight woman that had a weight gain of $22 \mathrm{~kg}$ at 40 weeks of gestation:

$$
Z=\frac{1}{0.128 *(-0.111)}\left[\left(\frac{42}{34.493}\right)^{-0.111}-1\right]=1.52
$$

Fig. 2 Equation for the calculation of pre-pregnancy body mass index-specific gestational weight gain $z$ scores based on a Box-Cox $t$ model ${ }^{a}$. a where $Y$ is weight gain at a certain gestational age, $L$ is lambda, $M$ is $\mathrm{mu}$, and $S$ is sigma. The random variable $Z$ is assumed to follow a $t$ distribution with degrees of freedom, Tau $>0$, treated as a continuous parameter. The parameters of our Box-Cox $t$ model for each pre-pregnancy body mass index group are provided for the rounded gestational ages. This equation can be applied on data using the y2z function of the AGD package in R. The function will allow the calculation of $z$ scores for the exact gestational age by extrapolating the parameters. For applying the equation or function, weight gain must be $>0$, because the model cannot deal with negative values. In order to fit the Box-Cox $t$ model, parameters were calculated based on weight gain $+20 \mathrm{~kg}$, and thus $20 \mathrm{~kg}$ must be added to weight gain to be able to use our parameters. The constant of $20 \mathrm{~kg}$ was chosen since $-20 \mathrm{~kg}$ is an extremely low value for weight change during pregnancy. After adding the $20 \mathrm{~kg}$, weight gain must be > 0 ; otherwise, the equation or function using our Box-Cox $t$ model parameters cannot be applied for the remaining $\leq 0$ values

remaining $70 \%$ comprises uterine and mammary tissue expansion, increased blood volume, extracellular fluid, and fat stores [17]. The US Institute of Medicine (IOM) published in 2009 the revised recommended gestational weight gain ranges, i.e., $12.5-18 \mathrm{~kg}, 11.5-16 \mathrm{~kg}$, 7$11.5 \mathrm{~kg}$, and 5-9 $\mathrm{kg}$ for underweight, normal weight, overweight, and obese women, respectively, based on findings from observational studies focused on associations of gestational weight gain with preterm birth, small, and large size for gestational age at birth, cesarean delivery, postpartum weight retention, and childhood obesity [1]. Both insufficient and excessive gestational weight gain, defined according to these guidelines, are risk factors of adverse maternal and child health outcomes [2-5]. In our study, insufficient, adequate, and excessive gestational weight gain was observed in $38.1 \%$, $43.8 \%$, and $18.1 \%$ of underweight women; $25.4 \%, 41.5 \%$, and $33.1 \%$ of normal weight women; $9.8 \%, 24.3 \%$, and $65.9 \%$ of overweight women; and $18.6 \%, 24.0 \%$, and $57.4 \%$ of obese women, respectively.

Gestational weight gain charts are important from a clinical and epidemiological perspective. From a clinical perspective, appropriate gestational weight gain charts can help to identify individuals at risk for adverse health outcomes. It has been recognized that it might be problematic to link total gestational weight gain with pregnancy outcomes that are highly correlated with gestational age at birth, such as preterm birth. Women who deliver at earlier gestational ages have less time to gain weight, which may lead to a spurious association between low gestational weight gain and preterm birth. The use of the rate of weight gain ( $\mathrm{kg}$ per week of gestation) reduces but does not entirely resolve this bias [2]. Weight gain for gestational age $z$ score charts can be used to classify weight gain independently of gestational age and provide a tool to establish the unbiased associations between gestational weight gain and pregnancy outcomes. This method enables comparison of weight gain of women who deliver at earlier gestational ages with weight gain of women with normal pregnancy duration at the same point in pregnancy. Although various gestational weight gain charts have previously been developed, these charts vary across different studies and still have methodological limitations [7-9, 18-29]. Based on a recent systematic review of 12 studies involving $2,268,556$ women from 9 countries, differences in the methodological quality of gestational weight gain studies may explain the varying chart recommendations. These charts were all derived from country-specific studies that varied in sample selection, study design, methods of data collection, and statistical analysis [6]. A study among 3097 normal weight women from Brazil, China, India, Italy, Kenya, Oman, UK, and USA described the patterns in maternal gestational weight gain from 14 weeks onwards in healthy pregnancies with good maternal and perinatal outcomes. The authors suggested that weight gain follows a linear trajectory throughout pregnancy, which was similar across the eight populations [7]. A hospital-based study developed gestational weight gain charts for 1047, 1202, 1267, and 730 overweight, grades 1,2 , and 3 obese US women, respectively, delivering uncomplicated term pregnancies. The rate of weight gain was minimal until 15-20 weeks and then increased in a slow, linear manner until term. The rate of weight gain was lower as BMI increased [8]. In a study among 141,767 Swedish women with term, non-anomalous, singleton pregnancies and no pre-existing hypertension or diabetes, the rate of weight gain also decreased with increasing BMI. In normal weight, overweight and grade 1 obese women, the median rate of weight gain was 

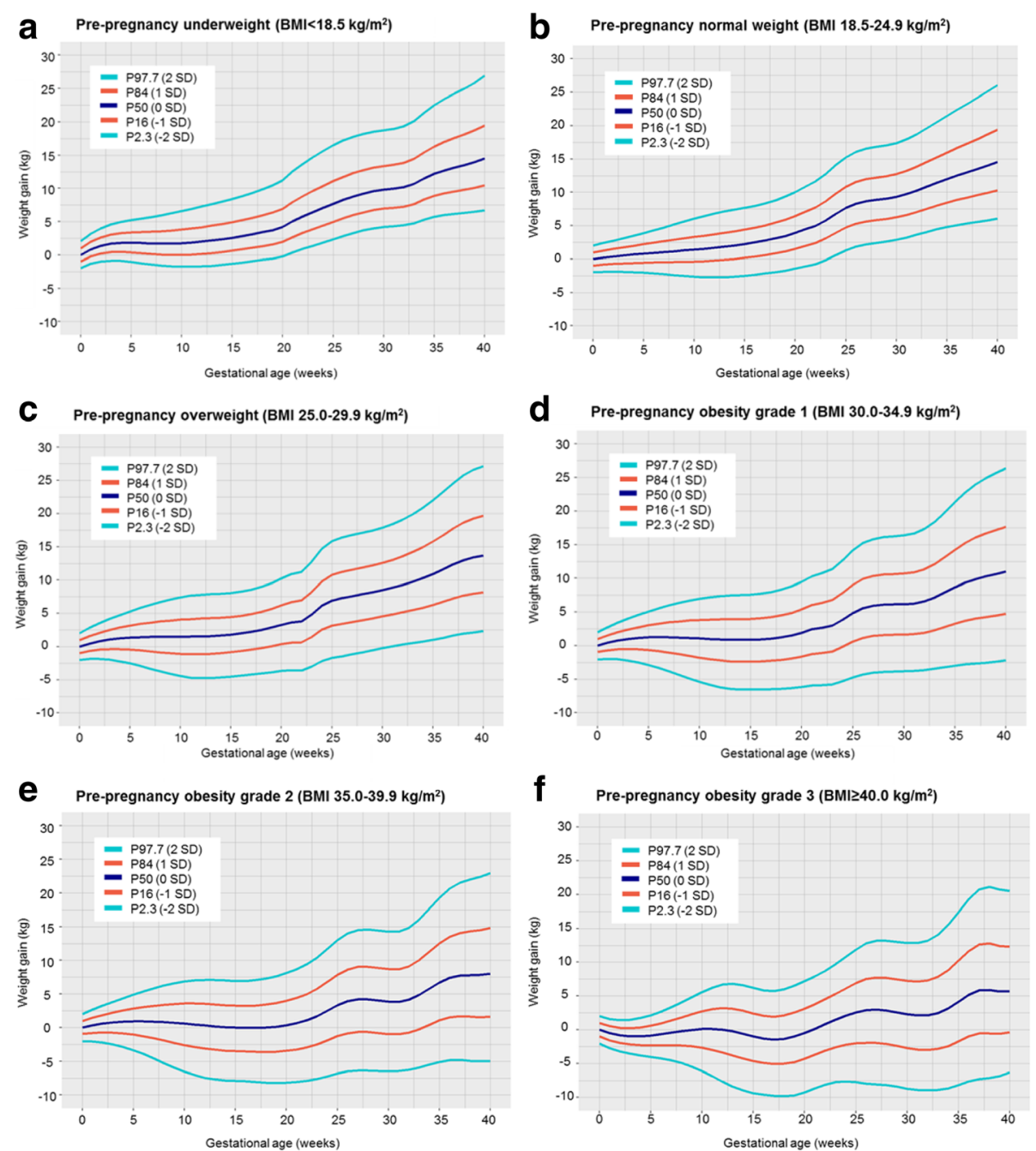

Fig. 3 Selected percentiles of weight gain for gestational age in women without any pregnancy complication for maternal pre-pregnancy underweight (a), normal weight (b), overweight $(\mathbf{c})$, obesity grade 1 (d), obesity grade 2 (e) and obesity grade 3 (f)

Table 2 Percentile 50 of gestational weight gain at 20 and 40 weeks for maternal pre-pregnancy body mass index groups in all pregnant women and in women without any pregnancy complication

\begin{tabular}{|c|c|c|c|c|}
\hline & \multicolumn{2}{|c|}{ P50 of weight gain $(\mathrm{kg})$ at 20 weeks } & \multicolumn{2}{|c|}{ P50 of weight gain $(\mathrm{kg})$ at 40 weeks } \\
\hline & $\begin{array}{l}\text { All pregnant } \\
\text { women }\end{array}$ & $\begin{array}{l}\text { Women without any pregnancy } \\
\text { complication }\end{array}$ & $\begin{array}{l}\text { All pregnant } \\
\text { women }\end{array}$ & $\begin{array}{l}\text { Women without any pregnancy } \\
\text { complication }\end{array}$ \\
\hline Underweight & 4.20 & 4.17 & 14.20 & 14.47 \\
\hline Normal weight & 3.90 & 3.91 & 14.49 & 14.53 \\
\hline Overweight & 3.35 & 3.28 & 13.86 & 13.68 \\
\hline $\begin{array}{l}\text { Obesity grade } \\
1\end{array}$ & 1.95 & 1.93 & 11.19 & 10.99 \\
\hline $\begin{array}{l}\text { Obesity grade } \\
2\end{array}$ & 0.93 & 0.34 & 8.73 & 8.02 \\
\hline $\begin{array}{l}\text { Obesity grade } \\
3\end{array}$ & -0.35 & -0.49 & 6.27 & 5.65 \\
\hline
\end{tabular}


minimal until 15 weeks, after which it increased in a linear manner until term whereas in underweight, and grades 2 and 3 obese women, the median rate of weight gain was steady throughout gestation [9]. The generalizability of these charts to other populations is not known.

In the current study, we constructed gestational weight gain reference charts for 218,216 underweight, normal weight, overweight, and grades 1, 2, and 3 obese women using data from cohorts from Europe, North America, and Oceania. We observed that for all maternal pre-pregnancy BMI groups, weight gain throughout pregnancy followed a non-linear trajectory. This finding is not consistent with results of previous studies that suggested that weight gain follows a linear trajectory at least from the second half of pregnancy onwards [7-9]. We included a large spectrum of gestational age and had a large number of participants and weight measurements available, enabling the detection of small variations in the weight gain patterns. The non-linearity of the trajectories was supported by advanced visual diagnostic methods for model choice and information criteria. This difference in the pattern of weight gain between our study and previous studies is not a result of longitudinal or cross-sectional modeling since the inclusion of the correlation structure among observations seems to have negligible effects on the location and precision of the centiles [13]. Therefore, from a statistical point of view, we believe that these charts describe the actual track of weight gain during pregnancy and that a simpler method assuming a linear weight gain fits the data less well. From a biological point of view, gestational weight gain reflects multiple fetal and maternal components [17]. This non-linearity might be the result of fluctuations in these components throughout pregnancy. This variation in the weight gain seems to be more pronounced in the obese groups. Also, contributing to this non-linearity, we observed a greater rate of weight gain around 2225 weeks, especially in overweight women, which might be related to the initiation of adipose tissue formation in the fetus that is known to occur between the 14th and the 23rd week of gestation [30]. In the current study, the rate of weight gain was greater in the second than in the first half of pregnancy and was lower as pre-pregnancy BMI was higher. Despite the range of cultures, behaviors, clinical practices, and traditions, which can strongly influence gestational weight gain, we did not observe differences in the patterns of weight gain between cohorts and countries. This finding might indicate that the biological process of gaining weight during pregnancy does not differ across different international populations in Europe, North America, and Oceania.

Gestational weight gain charts can be classified as reference charts or standard charts. A reference chart is based on a sample of the general population and is descriptive, whereas a standard chart is only focused on a healthy population and is prescriptive. The use of references or standards might influence the chart recommendations. Gestational weight gain standards might be biased by the definition of what constitutes a healthy population, especially for overweight and obese women, and might be compromised by an inadequate sample size. The INTERGROWTH-21st Project developed standards in an international population of normal weight women by only including women with healthy pregnancies with good maternal and perinatal outcomes [7]. However, a recent study showed that the INTERGROWTH-21st standards do not seem to describe optimal weight gain patterns with respect to maternal postpartum weight retention and thus may still be descriptive [31]. We developed gestational weight gain reference charts by including all pregnant women that had all necessary information available for these analyses and compared with the charts obtained in a sample with good maternal and perinatal outcomes. We observed similar weight gain patterns for each maternal BMI group in all pregnant women and in women without any pregnancy complication. Thus, our reference charts are largely similar to those obtained in a sample restricted to uncomplicated term pregnancies, were developed in a large sample, enabling relatively accurate charts for women with severe obesity, and were less likely to bias in the definition of the population. We consider our reference charts as appropriate charts for clinical practice and epidemiological research. However, future studies are needed to relate the derived reference charts to maternal and offspring outcomes and to create customized weight gain charts by including factors such as parity and ethnicity. Finally, since the causality for the associations of maternal gestational weight gain with maternal and child's health outcomes remain unclear, practicing prenatal care on weight gain is still debatable [32, 33]. A further unanswered question is whether alteration of these gestational weight gain patterns is achievable as, to date, randomized controlled trials focused on lifestyle interventions during pregnancy have shown only small reductions in gestational weight gain [33-35].

\section{Strengths and limitations}

Strengths of this study were the description of the pattern of weight gain throughout pregnancy in a large sample of pregnant women from 33 cohorts from Europe, North America, and Oceania. However, our chart for grade 3 obese women would have benefited from a larger sample and thus the values of selected percentiles in our chart may differ from the true values in the underlying population. We included data from cohort studies from Europe, North America, and Oceania but a 
large proportion of data come from Northern Europe. This suggests that our charts might be generalizable to Western populations and specifically to populations of Northern European ancestry. Further studies are needed to develop gestational weight gain charts among populations from low- to middle-income countries and of different ethnic backgrounds. Since most studies were general population-based cohort studies, we might have an overrepresentation of the healthier population due to selective non-response in the participating cohorts. This might have underestimated the prevalence of inadequate and excessive gestational weight gain and of the adverse health outcomes. However, we observed similar findings in the full group and when we restricted our analyses to women with uncomplicated pregnancies, which suggest no strong bias due to selection in the cohorts. Also, due to the data request format within this collaboration, only one weight measurement at early, mid, and late pregnancy was obtained, when available, for each woman even if multiple weight measurements were taken during each period. This might have limited the number of weight measurements available for the creation of these charts. For our analyses, we had available weight measurements at the start of pregnancy and subsequent weights from 8 weeks onwards. The lack of weight measurements during the beginning of pregnancy could have influenced the modeling of weight gain patterns, but we believe this is unlikely since not much variation is expected during this period. The correlation between weight at the start of pregnancy and weight at 8 weeks of gestation was 0.99 and an intraclass correlation coefficient using an absolute agreement definition of 97.9\% was obtained through a two-way mixed effects model. Finally, we relied not only on weight data obtained by measurements and derived from clinical records but also on self-reported data, which might be a source of error. Women tend to underestimate their weight on self-report [36]. An underestimation of pre-pregnancy weight might lead to a misclassification of women in the different BMI groups and to an overestimation of weight gain at each specific week of gestation. Since measured pre-pregnancy weight is rarely available in routine clinical practice, our reference charts reflect the information usually used to assess weight gain in the prenatal care. Methods of gestational age assessment might also be prone to error, leading to some inaccuracy in the gestational weight gain percentiles and $z$ scores, though the error in gestational age estimates and thus the influence on our results is likely to be small. For the construction of the standards, we excluded women based on direct pregnancy-related complications, such as hypertensive or diabetic disorders, preterm deliveries, and small or large for gestational age at birth infants. Unfortunately, information about excess postpartum weight retention and infant deaths was not available.

\section{Conclusions}

We developed gestational weight gain reference charts for different pre-pregnancy BMI groups for women in Europe, North America, and Oceania. Gestational weight gain strongly differed per maternal pre-pregnancy BMI group and was gradually lower across higher BMI groups. These reference charts can be used to classify weight gain independently of gestational age in etiological research focused on maternal and offspring consequences of weight gain. Future research is needed that relates these charts with a broad range of maternal and child health outcomes. These charts may be useful in clinical practice to identify women at risk for adverse short- and long-term health outcomes.

\section{Additional file}

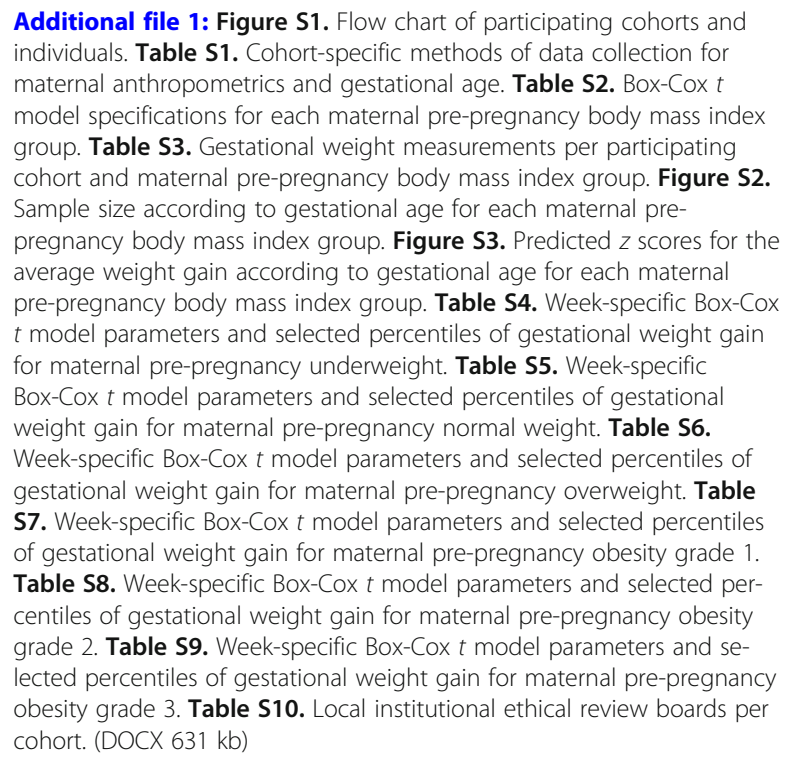

\section{Acknowledgements}

$\mathrm{ABCD}$

The authors especially thank all participating mothers and their children, and are grateful to all obstetric care providers in Amsterdam for their

contribution to the data collection of the ABCD-study.

ALSPAC

The authors are extremely grateful to all the families who took part in this study, the midwives for their help in recruiting them, and the whole ALSPAC team, which includes interviewers, computer and laboratory technicians, clerical workers, research scientists, volunteers, managers, receptionists, and nurses.

$\mathrm{AOB} / \mathrm{F}$

The authors acknowledge the contribution and support of All Our Families participants and team.

DNBC

The authors thank all the families for participating in the Danish National Birth Cohort.

EDEN

The authors thank the EDEN mother-child cohort study group, whose members are I. Annesi-Maesano, J.Y. Bernard, J. Botton, M.A. Charles, P. Dargent-Molina, B. de Lauzon-Guillain, P. Ducimetière, M. de Agostini, B. Foliguet, A. Forhan, X. Fritel, A. Germa, V. Goua, R. Hankard, B. Heude, M. Kaminski, B. Larroquet, N. Lelong, J. 
Lepeule, G. Magnin, L. Marchand, C. Nabet, F Pierre, R. Slama, M.J. SaurelCubizolles, M. Schweitzer, and O. Thiebaugeorges.

FCOU

The authors wish to acknowledge the University of Illinois at Chicago School of Public Health's Louise Hamilton Kyiv Data Management Center for their assistance in the data management for FCOU study.

GASPII

The authors acknowledge the families involved in the study.

GECKO Drenthe

The authors are grateful to the families who took part in the GECKO Drenthe study, the midwives, gynecologists, nurses, and GPs for their help for recruitment and measurement of participants, and the whole team from the GECKO Drenthe study.

Generation R

The authors gratefully acknowledge the contribution of general practitioners, hospitals, midwives, and pharmacies in Rotterdam.

Generation XXI

The authors gratefully acknowledge the families enrolled in Generation XXI for their kindness, all members of the research team for their enthusiasm and perseverance, and the participating hospitals and their staff for their help and support.

GENESIS

The authors thank the Genesis research group which was comprised from Evdokia Oikonomou, Vivian Detopoulou, Christine Kortsalioudaki, Margarita Bartsota, Thodoris Liarigkovinos, and Christos Vassilopoulos.

Gen3G

The authors acknowledge the support form clinical and research staff from blood sampling in pregnancy clinic at the Centre Hospitalier Universitaire de Sherbrooke (CHUS) for their help in recruitment, and the CHUS biomedical laboratory for performing assays.

GINIplus

The authors thank all the families for their participation in the GINIplus study. Furthermore, the authors thank all members of the GINIplus Study Group for their excellent work. The GINIplus Study group consists of the following: Institute of Epidemiology I, Helmholtz Zentrum München, German Research Center for Environmental Health, Neuherberg (Heinrich J, Brüske I, Schulz H, Flexeder C, Zeller C, Standl M, Schnappinger M, Ferland M, Thiering E, Tiesler C); Department of Pediatrics, Marien-Hospital, Wesel (Berdel D, von Berg A); Ludwig-MaximiliansUniversity of Munich, Dr. von Hauner Children's Hospital (Koletzko S); Child and Adolescent Medicine, University Hospital rechts der Isar of the Technical University Munich (Bauer CP, Hoffmann U); IUF-Environmental Health

Research Institute, Düsseldorf (Schikowski T, Link E, Klümper C, Krämer U, Sugiri D). HUMIS

The authors thank the mothers who participated in the study and the Norwegian Research Council for their continuous support through several grants. INMA-Valencia

The authors would particularly like to thank all the participants for their generous collaboration.

INMA-Gipuzkoa

The authors thank the children and parents who participated to the INMAGipuzkoa study.

INMA-Menorca

The authors thank all the participants for their generous collaboration. The authors are grateful to Mireia Garcia, Maria Victoria Estraña, Maria Victoria Iturriaga, Cristina Capo, and Josep LLuch for their assistance in contacting the families and administering the questionnaires.

KOALA

The authors thank the children and parents who participated to the KOALA study. Krakow Cohort

The authors acknowledge Jagiellnonian University Medical College in Krakow and Columbia University in New York. Principal investigator: Prof. FP Perera; co-investigator: Prof. W Jedrychowski.

LISAplus

The authors thank all the families for their participation in the LISAplus study. Furthermore, the authors thank all members of the LISAplus Study Group for their excellent work. The LISAplus Study group consists of the following: Helmholtz Zentrum München, German Research Center for Environmental Health, Institute of Epidemiology I, Munich (Heinrich J, Schnappinger M, Brüske I, Ferland M, Schulz H, Zeller C, Standl M, Thiering E, Tiesler C,
Flexeder C); Department of Pediatrics, Municipal Hospital "St. Georg", Leipzig (Borte M, Diez U, Dorn C, Braun E); Marien Hospital Wesel, Department of Pediatrics, Wesel (von Berg A, Berdel D, Stiers G, Maas B); Pediatric Practice, Bad Honnef (Schaaf B); Helmholtz Centre of Environmental Research-UFZ, Department of Environmental Immunology/Core Facility Studies, Leipzig (Lehmann I, Bauer M, Röder S, Schilde M, Nowak M, Herberth G, Müller J); Technical University Munich, Department of Pediatrics, Munich (Hoffmann U, Paschke M, Marra S); Clinical Research Group Molecular Dermatology, Department of Dermatology and Allergy, Technische Universität München (TUM), Munich (Ollert M, J. Grosch).

LUKAS

The authors thank all the families for their participation in the study. The authors are grateful to Raija Juntunen, Asko Vepsäläinen, Pekka Tiittanen, and Timo Kauppila for their contribution to the data collection and data management.

MoBa

The authors are grateful to all the participating families in Norway who take part in this on-going cohort study.

NINFEA

The authors thank all families participating in the NINFEA cohort.

PÉLAGIE

The authors thank the gynecologists, obstetricians, ultrasonographers, midwives, pediatricians, and families who participated in the study. PIAMA

The authors thank the PIAMA participants for their ongoing collaboration. Piccolipiù

The authors acknowledge the Piccolipiù Working Group and the families involved in the study.

PRIDE Study

The authors thank the mothers and infants who participate in this ongoing cohort study, as well as all midwives, gynecologists, and general practitioners for their contributions to the data collection.

Project Viva

The authors thank the Project Viva mothers, children, and families for their ongoing participation.

RAINE Study

The authors would like to acknowledge the Raine Study participants and their families. We would also like to acknowledge the Raine Study Team for study co-ordination and data collection, and the NH\&MRC for their longterm contribution to funding the study over the last 29 years.

REPRO_PL

The authors would particularly like to thank all the cohort participants for their collaboration.

RHEA

The authors would particularly like to thank all the cohort participants for their generous collaboration.

Slovak PCB study

The authors thank the Slovak PCB study participants for their ongoing cooperation.

STEPS

The authors are grateful to all the families who took part in STEPS study. SWS

The authors are grateful to the women of Southampton who gave their time to take part in the Southampton Women's Survey and to the research nurses and other staff who collected and processed the data.

\section{Role of the funder}

FCOU

Investigators from the US National Institute of Environmental Health Scientists (NIEHS) were involved in the design of the birth outcomes phase of the FCOU study.

The other cohorts declared that the funding agencies had no role in the design and conduct of the study; collection, management, analysis, and interpretation of data; preparation, review, and approval of manuscript; or decision to submit manuscript for publication.

\section{Funding}

$\mathrm{ABCD}$

This work was supported by the Netherlands Organization for Health Research and Development (ZonMw) (TOP grant, 40-00812-98-11010). 
ALSPAC

The UK Medical Research Council and Wellcome (Grant ref.: 102215/2/13/2) and the University of Bristol provide core support for ALSPAC. This study has received support from the US National Institute of Health (R01 DK10324) and European Research Council under the European Union's Seventh Framework Programme (FP7/2007-2013)/ERC grant agreement no 669545. DA Lawlor works in a unit that receives UK MRC funding (MC_UU_12013/5) and is an NIHR senior investigator (NF-SI-0611-10196).

$\mathrm{AOB} / \mathrm{F}$

All Our Families is funded through Alberta Innovates Interdisciplinary Team Grant \#200700595, the Alberta Children's Hospital Foundation, and the Max Bell Foundation.

Co.N.ER

No funding reported.

DNBC

The Danish National Research Foundation has established the Danish Epidemiology Science Centre that initiated and created the Danish National Birth Cohort. The cohort is furthermore a result of a major grant from this foundation. Additional support for the Danish National Birth Cohort is obtained from the Pharmacy Foundation, the Egmont Foundation, the March of Dimes Birth Defects Foundation, the Augustinus Foundation, and the Health Foundation. The DNBC 7-year follow-up is supported by the Lundbeck Foundation (195/04) and the Danish Medical Research Council (SSVF 0646).

EDEN

The EDEN study was supported by Foundation for medical research (FRM), National Agency for Research (ANR), National Institute for Research in Public health (IRESP: TGIR cohorte santé 2008 program), French Ministry of Health (DGS), French Ministry of Research, INSERM Bone and Joint Diseases National Research (PRO-A) and Human Nutrition National Research Programs, ParisSud University, Nestlé, French National Institute for Population Health Surveillance (InVS), French National Institute for Health Education (INPES), the European Union FP7 programmes (FP7/2007-2013, HELIX, ESCAPE, ENRIECO, Medall projects), Diabetes National Research Program (through a collaboration with the French Association of Diabetic Patients (AFD)), French Agency for Environmental Health Safety (now ANSES), Mutuelle Générale de l'Education Nationale a complementary health insurance (MGEN), French national agency for food security, French-speaking association for the study of diabetes and metabolism (ALFEDIAM).

FCOU

FCOU study is supported by the US National Institutes of Health Fogarty International Center, US NIEHS, US CDC, US EPA, and National Academy of Medical Sciences of Ukraine.

GASPII

Ministry of Health.

GECKO Drenthe

The GECKO Drenthe birth cohort was funded by an unrestricted grant of Hutchison Whampoa Ld, Hong Kong and supported by the University of Groningen, Well Baby Clinic Foundation Icare, Noordlease, Paediatric

Association Of The Netherlands and Youth Health Care Drenthe. Generation R

The general design of the Generation R Study is made possible by financial support from the Erasmus MC, University Medical Center, Rotterdam, Erasmus University Rotterdam, Netherlands Organization for Health Research and Development (ZonMw), Netherlands Organisation for Scientific Research (NWO), Ministry of Health, Welfare and Sport and Ministry of Youth and Families. Research leading to these results has received funding from the European Union's Seventh Framework Programme (FP7/2007-2013), project EarlyNutrition under grant agreement no. 289346, the European Union's Horizon 2020 research and innovation programme under grant agreement no. 633595 (DynaHEALTH) and the European Union's Horizon 2020 research and innovation programme under grant agreement 733206 (LifeCycle Project). Romy Gaillard received funding from the Dutch Heart Foundation (grant number 2017T013) and the Dutch Diabetes Foundation (grant number 2017.81.002). Vincent Jaddoe received grants from the Netherlands Organization for Health Research and Development (VIDI 016.136.361) and the European Research Council (Consolidator Grant, ERC-2014-CoG-648916). Generation XXI

Generation XXI was funded by Programa Operacional de Saúde-Saúde XXI, Quadro Comunitário de Apoio III and Administração Regional de
Saúde Norte (Regional Department of Ministry of Health). This study was funded by FEDER through the Operational Programme Competitiveness and Internationalization and national funding from the Foundation for Science and Technology-FCT (Portuguese Ministry of Science, Technology and Higher Education) (POCl-01-0145-FEDER-016837), under the project "PathMOB.: Risco cardiometabólico na infância: desde o início da vida ao fim da infância" (Ref. FCT PTDC/DTP-EPI/3306/2014) and the Unidade de Investigação em Epidemiologia-Instituto de Saúde Pública da Universidade do Porto (EPIUnit) (POCl-01-0145-FEDER-006862; Ref. UID/DTP/04750/2013). AC Santos holds a FCT Investigator contract IF/ 01060/2015.

GENESIS

The study was supported by a research grant from Friesland Foods Hellas. Gen3G

Gen3G was supported by a Fonds de recherche du Québec en santé (FRQ-S) operating grant (grant \#20697); a Canadian Institute of Health Reseach (CIHR) Operating grant (grant \#MOP 115071); a Diabète Québec grant and a Canadian Diabetes Association operating grant (grant \#OG-3-08-2622-JA). GINIplus

The GINIplus study was mainly supported for the first 3 years of the Federal Ministry for Education, Science, Research and Technology (interventional arm) and Helmholtz Zentrum Munich (former GSF) (observational arm). The 4-year, 6-year, 10-year, and 15-year follow-up examinations of the GINIplus study were covered from the respective budgets of the 5 study centers (Helmholtz Zentrum Munich (former GSF), Research Institute at MarienHospital Wesel, LMU Munich, TU Munich and from 6 years onwards also from IUF-Leibniz Research-Institute for Environmental Medicine at the University of Düsseldorf) and a grant from the Federal Ministry for Environment (IUF Düsseldorf, FKZ 20462296). Further, the 15 year follow-up examination of the GINIplus study was supported by the Commission of the European Communities, the 7th Framework Program: MeDALL project, and as well by the companies Mead Johnson and Nestlé.

HUMIS

European Community's Seventh Framework Programme (FP7/2007-2013) under grant agreements Early Nutrition no. 289346 and by funds from the Norwegian Research Council's MILPAAHEL programme, project no. 213148. INMA-Sabadell

This study was funded by grants from the Instituto de Salud Carlos III (Red INMA G03/176) and the Generalitat de Catalunya-CIRIT (1999SGR 00241). INMA-Valencia

This study was funded by Grants from UE (FP7-ENV-2011 cod 282957 and HEALTH.2010.2.4.5-1), Spain: ISCIII (G03/176; FIS-FEDER: PI09/02647, PI11/ 01007, PI11/02591, PI11/02038, PI13/1944, PI13/2032, PI14/00891, PI14/01687, and PI16/1288; Miguel Servet-FEDER CP11/00178, CP15/00025, and CPII6/ 00051), and Generalitat Valenciana: FISABIO (UGP 15-230, UGP-15-244, and UGP-15-249).

INMA-Gipuzkoa

This study was funded by grants from the Instituto de Salud Carlos III (FISFIS PI06/0867, FIS-PS09/0009) 0867, Red INMA G03/176) and the Departamento de Salud del Gobierno Vasco (2005111093 and 2009111069) and the Provincial Government of Guipúzcoa (DFG06/004 and FG08/001).

INMA-Menorca

This study was funded by grants from the Instituto de Salud Carlos III (Red INMA G03/176).

KOALA

Data collection for the KOALA study from pregnancy up to age 1 year was financially supported by grants from Royal Friesland Foods (Leeuwarden); Triodos Foundation (Zeist); Phoenix Foundation; Raphaël Foundation; Iona Foundation; Foundation for the Advancement of Heilpedagogie (all in the Netherlands).

Krakow Cohort

The study received funding from a NIEHS R01 grants entitled: "Vulnerability of the Fetus/Infant to PAH, PM2.5 and ETS" and "Developmental effects of early-life exposure to airborne PAH" (R01ES010165 and R01ES015282) and from The Lundin Foundation, The John and Wendy Neu Family Foundation, The Gladys and Roland Harriman Foundation and an Anonymous Foundation.

LISAplus

The LISAplus study was mainly supported by grants from the Federal Ministry for Education, Science, Research and Technology and in addition 
from Helmholtz Zentrum Munich (former GSF), Helmholtz Centre for Environmental Research-UFZ, Leipzig, Research Institute at MarienHospital Wesel, Pediatric Practice, Bad Honnef for the first 2 years. The 4-year, 6-year, 10-year, and 15-year follow-up examinations of the LISAplus study were covered from the respective budgets of the involved partners (Helmholtz Zentrum Munich (former GSF), Helmholtz Centre for Environmental Research-UFZ, Leipzig, Research Institute at MarienHospital Wesel, Pediatric Practice, Bad Honnef, IUF-Leibniz-Research Institute for Environmental Medicine at the University of Düsseldorf) and in addition by a grant from the Federal Ministry for Environment (IUF Düsseldorf, FKZ 20462296). Further, the 15-year follow-up examination of the LISAplus study was supported by the Commission of the European Communities and the 7th Framework Program: MeDALL project.

LUKAS

The grants from the Academy of Finland (grants 139021;287675); the Juho Vainio Foundation; the Foundation for Pediatric Research; EVONTR-funding; Päivikki and Sakari Sohlberg Foundation; The Finnish Cultural Foundation; European Union QLK4-CT-2001-00250; and by the National Institute for Health and Welfare, Finland. $\mathrm{MoBa}$

The Norwegian Mother and Child Cohort Study is supported by the Norwegian Ministry of Health and Care Services and the Ministry of Education and Research, NIH/NIEHS (contract no. N01-ES-75558), NIH/NINDS (grant no. 1 UO1 NS 047537-01 and grant no. 2 UO1 NS 047537-06A1). NINFEA

The NINFEA cohort was partially funded by the Compagnia San Paolo Fundation and by the Piedmont Region.

PÉLAGIE

The Pélagie cohort was supported by the French National Research Agency (ANR-2010-PRSP-007) and the French Research Institute for Public Health (AMC11004NSA-DGS).

PIAMA

The PIAMA study was supported by the Netherlands Organization for Health Research and Development; The Netherlands Organization for Scientific Research; The Netherlands Asthma Fund; The Netherlands Ministry of Spatial Planning, Housing, and the Environment; and The Netherlands Ministry of Health, Welfare, and Sport.

Piccolipiù

The Piccolipiù project was financially supported by the Italian National Center for Disease Prevention and Control (CCM grants years 2010 and 2014) and by the Italian Ministry of Health (art 12 and 12 bis D.lgs 502/92).

PRIDE Study

The PRIDE Study is supported by grants from the Netherlands Organization for Health Research and Development, the Radboud Institute for Health

Sciences, and the Lung Foundation Netherlands.

Project Viva

National Institutes of Health (R01 HD034568, UG3OD023286).

RAINE Study

The Western Australian Pregnancy Cohort (Raine Study) has been funded by program and project grants from the Australian National Health and Medical Research Council, the Commonwealth Scientific and Industrial Research Organization, Healthway, and the Lions Eye Institute in Western Australia. The University of Western Australia (UWA), Curtin University, the Raine Medical Research Foundation, the Telethon Kids Institute, the Women's and Infant's Research Foundation (KEMH), Murdoch University, The University of Notre Dame Australia, and Edith Cowan University provide funding for the Core Management of the Raine Study.

REPRO_PL

National Science Centre, Poland, under the grant DEC-2014/15/B/NZ7/00998, FP7 HEALS Grant No. 603946 and the Ministry of Science and Higher Education under grant agreement no. 3068/7.PR/2014/2.

RHEA

The "Rhea" project was financially supported by European projects (EU FP62003-Food-3-NewGeneris, EU FP6. STREP Hiwate, EU FP7 ENV.2007.1.2.2.2.

Project No. 211250 Escape, EU FP7-2008-ENV-1.2.1.4 Envirogenomarkers, EU FP7-HEALTH-2009-single stage CHICOS, EU FP7 ENV.2008.1.2.1.6. Proposal No. 226285 ENRIECO, EU-FP7-HEALTH-2012 Proposal No. 308333 HELIX) and the Greek Ministry of Health (Program of Prevention of obesity and neurodevelopmental disorders in preschool children, in Heraklion District, Crete, Greece:
2011-2014; "Rhea Plus": Primary Prevention Program of Environmental Risk Factors for Reproductive Health, and Child Health: 2012-15).

Slovak PCB study

Support was provided by US National Institutes of Health grants R01 CA096525, R03 TW007152, P30 ES001247, and K12 ES019852.

STEPS

This study was supported by the University of Turku, Abo Akademi University, the Turku University Hospital, and the City of Turku, as well as by the Academy of Finland (grants 121569 and 123571), the Juho Vainio Foundation, the Yrjö Jahnsson Foundation, the Turku.

SWS

The SWS is supported by grants from the Medical Research Council, National Institute for Health Research Southampton Biomedical Research Centre, University of Southampton and University Hospital Southampton National Health Service Foundation Trust, and the European Union's Seventh Framework Programme (FP7/2007-2013), project EarlyNutrition (grant 289346). Study participants were drawn from a cohort study funded by the Medical Research Council and the Dunhill Medical Trust.

\section{Availability of data and materials}

The datasets generated and analyzed during the current study are available upon request to the cohorts.

\section{Authors' contributions}

SS and IE had full access to all of the data in the study and take responsibility for the integrity of the data and the accuracy of the data analysis. SS, RG, and WWV contributed to the study concept and design. SS, IE, SVB, and WWJ helped in the analysis and interpretation of data. SS and WWJ drafted the manuscript. All authors helped in the critical revision of the manuscript for important intellectual content. All authors read and approved the final manuscript.

\section{Ethics approval and consent to participate}

Cohorts were approved by their local institutional ethical review boards (information per cohort is given in Additional file 1: Table S10) and consent to participate was obtained from participants.

\section{Consent for publication}

Not applicable.

\section{Competing interests}

Keith M. Godfrey has received reimbursement for speaking at conferences sponsored by companies selling nutritional products and is part of an academic consortium that has received research funding from Abbott Nutrition, Nestec, and Danone. Debbie A. Lawlor has received support from Roche Diagnostics and Medtronic in relation to biomarker research that is not related to the research presented in this paper. Andrea von Berg has received reimbursement for speaking at symposia sponsored by Nestlé and Mead Johnson, who partly financially supported the 15 years follow-up examination of the GINIplus study. The rest of the authors reported no conflicts of interest.

\section{Publisher's Note}

Springer Nature remains neutral with regard to jurisdictional claims in published maps and institutional affiliations.

\section{Author details}

${ }^{1}$ The Generation R Study Group, Erasmus MC, University Medical Center Rotterdam, PO Box 2040, 3000 CA Rotterdam, the Netherlands. Department of Pediatrics, Sophia Children's Hospital, Erasmus MC, University Medical Center Rotterdam, Rotterdam, the Netherlands. ${ }^{3}$ TNO Child Health, Leiden, the Netherlands. ${ }^{4}$ Department of Epidemiology and Biostatistics, VU University Medical Center, Amsterdam, the Netherlands. ${ }^{5}$ EPIUnit-Instituto de Saúde Pública, Universidade do Porto, Rua das Taipas, n 135, 4050-600 Porto, Portugal. ${ }^{6}$ Department of Public Health and Forensic Sciences and Medical Education, Unit of Clinical Epidemiology, Predictive Medicine and Public Health, University of Porto Medical School, Porto, Portugal. ' INSERM, UMR1153 Epidemiology and Biostatistics Sorbonne Paris Cité Center (CRESS), ORCHAD Team, Villejuif, France. ${ }^{8}$ Paris Descartes University, Villejuif, France. ${ }^{9}$ Department of Preventive Medicine, Keck School of Medicine, University of 
Southern California, Los Angeles, CA, USA. ${ }^{10}$ Department of Social Medicine, Faculty of Medicine, University of Crete, Heraklion, Greece. ${ }^{11}$ Department of Genetics and Cell Biology, Maastricht University, Maastricht, the Netherlands. ${ }^{12}$ Inserm UMR 1085, Irset-Research Institute for Environmental and Occupational Health, F-35000 Rennes, France. ${ }^{13}$ First Department of Pediatrics, Athens University Medical School, Aghia Sophia Children's Hospital, National and Kapodistrian University of Athens, Athens, Greece. ${ }^{14}$ Department of Epidemiology, University Medical Center Groningen, University of Groningen, P.O. Box 30.001, 9700 RG Groningen, the Netherlands. ${ }^{15}$ MRC Lifecourse Epidemiology Unit, University of Southampton, Southampton, UK. ${ }^{16} \mathrm{Centre}$ de Recherche du Centre Hospitalier de I'Universite de Sherbrooke, Sherbrooke, QC, Canada. ${ }^{17}$ Department of Exposure and Environmental Epidemiology, Norwegian Institute of Public Health, Oslo, Norway. ${ }^{18}$ The Department of Biomedical and Neuromotor Sciences, University of Bologna, Bologna, Italy. ${ }^{19}$ Department of Epidemiology, Lazio Regional Health Service, Rome, Italy. ${ }^{20}$ Department of Woman and Child Health, Ospedale Versilia, Local Health Authority Toscana Nord Ovest, Viareggio, Italy. ${ }^{21} \mathrm{NIHR}$ Southampton Biomedical Research Centre, University of Southampton and University Hospital Southampton NHS Foundation Trust, Southampton, UK. ${ }^{22}$ Division of Metabolic and Nutritional Medicine, Dr. von Hauner Children's Hospital,

Ludwig-Maximilian-Universität Munich, 80337 Munich, Germany.

${ }^{23}$ Department of Environmental Epidemiology, Nofer Institute of Occupational Medicine, Lodz, Poland. ${ }^{24}$ Department of Public Health Sciences, School of Medicine, University of California Davis, Davis, CA 95616, USA. ${ }^{25}$ Department of Population Medicine, Harvard Medical School, Harvard Pilgrim Health Care Institute, Boston, MA, USA. ${ }^{26}$ Diabetes Unit, Massachusetts General Hospital, Boston, MA, USA. ${ }^{27}$ Center for Global Health, University of Illinois College of Medicine, Chicago, IL, USA. ${ }^{28}$ Telethon Kids Institute, The University of Western Australia, Perth, WA, Australia.

${ }^{29}$ Departments of Public Health Sciences and Environmental Medicine, University of Rochester School of Medicine and Dentistry, Rochester, NY, USA. ${ }^{30}$ Department of Health Security, National Institute for Health and Welfare, Kuopio, Finland. ${ }^{31}$ MRC Integrative Epidemiology Unit, University of Bristol, Oakfield House, Oakfield Grove, Bristol BS8 2BN, UK. ${ }^{32}$ Population Health Science, Bristol Medical School, University of Bristol, Bristol BS8 2BN, UK. ${ }^{33}$ Department of Public Health, University of Turku, Turku, Finland. ${ }^{34}$ Department of Environmental Immunology/Core Facility Studies, Helmholtz Centre for Environmental Research-UFZ, Leipzig, Germany. ${ }^{35}$ Epidemiology and Environmental Health Joint Research Unit, FISABIO-Universitat Jaume I -Universitat de València, Valencia, Spain. ${ }^{36}$ CIBER Epidemiología y Salud Pública (CIBERESP), Madrid, Spain. ${ }^{37}$ Division of Health Data and Digitalization, Norwegian Institute of Public Health, Oslo, Norway. ${ }^{38}$ Department of Epidemiology, Chair of Epidemiology and Preventive Medicine, Jagiellonian University Medical College, Krakow, Poland. ${ }^{39}$ Turku Centre for Biotechnology, University of Turku and Abo Akademi University, Turku, Finland. ${ }^{40}$ Department of Nutrition and Dietetics, School of Health Science and Education, Harokopio University, Athens, Greece. ${ }^{41}$ Department of Pediatrics, Cumming School of Medicine, University of Calgary, Calgary, Alberta, Canada. ${ }^{42}$ Department of Epidemiology, Care and Public Health Research Institute, Maastricht University, Maastricht, the Netherlands. ${ }^{43}$ National Institute of Public Health, University of Southern Denmark, Copenhagen, Denmark. ${ }^{44}$ Department of Public Health, Section of Epidemiology, University of Copenhagen, Øster Farimagsgade 5, 1014 Copenhagen, Denmark. ${ }^{45}$ Department of Rehabilitation, Nutrition and Sport, La Trobe University, Melbourne, Australia. ${ }^{46}$ Department of Environmental Medicine, Faculty of Public Health, Slovak Medical University, Bratislava, Slovak Republic. ${ }^{47}$ School of Women's and Infants' Health, University of Western Australia, Crawley, Western Australia, Australia. ${ }^{48}$ Research Unit for Gynaecology and Obstetrics, Institute for Clinical Research, University of Southern Denmark, Odense, Denmark. ${ }^{49}$ Department of Public Health, Amsterdam Public Health Research Institute, Academic Medical Center, Amsterdam, the Netherlands. ${ }^{50}$ Department of Environmental Exposures and Epidemiology, Domain of Infection Control and Environmental Health, Norwegian Institute of Public Health, Lovisenberggata 8, 0477 Oslo, Norway. ${ }^{51}$ Department of Public Health, University of Helsinki, Helsinki, Finland. ${ }^{52}$ Department of Medical Sciences, University of Turin, Turin, Italy. ${ }^{53}$ Department for Health Evidence, Radboud Institute for Health Sciences, Radboud University Medical Center, Nijmegen, the Netherlands. ${ }^{54}$ Subdirección de Salud Pública Gipuzkoa, San Sebastián, Spain. ${ }^{55}$ Instituto de Investigación Sanitaria BIODONOSTIA, San Sebastián, Spain. ${ }^{56}$ Julius Center for Health Sciences and Primary Care, University Medical Center Utrecht, Utrecht University, Utrecht, the Netherlands. ${ }^{57}$ The Novo Nordisk Foundation Center for Basic Metabolic Research, Section of Metabolic Genetics, Faculty of Health and Medical Sciences, University of Copenhagen, Copenhagen, Denmark. ${ }^{58}$ Institute of Epidemiology, Helmholtz Zentrum München-German Research Center for Environmental Health, Neuherberg, Germany. ${ }^{59} \mathrm{School}$ of Public Health, University of Colorado, Aurora, Colorado, USA. ${ }^{60}$ Norwegian Institute of Public Health, Oslo, Norway. ${ }^{61}$ Department of Global Public Health and Primary Care, University of Bergen, Bergen, Norway. ${ }^{62}$ Dr. von Hauner Children's Hospital, Ludwig-Maximilians-University Munich, Munich, Germany. ${ }^{63} \mathrm{lb}$-salut, Area de Salut de Menorca, Menorca, Spain.

${ }^{64}$ Department of Community Health Sciences, Cumming School of Medicine, University of Calgary, Calgary, Alberta, Canada. ${ }^{65}$ Department of Environmental Medicine, Slovak Medical University, Bratislava 833 03, Slovak Republic. ${ }^{66}$ Radboud REshape Innovation Center, Radboud University Medical Center, Nijmegen, the Netherlands. ${ }^{67}$ Department of Pediatrics, Marien-Hospital Wesel, Research Institute, Wesel, Germany. ${ }^{68}$ ISGlobal, Institute for Global Health, Barcelona, Spain. ${ }^{69}$ Universitat Pompeu Fabra (UPF), Barcelona, Spain. ${ }^{70}$ Department of Medical and Social Problems of Family Health, Institute of Pediatrics, Obstetrics and Gynecology, Kyiv, Ukraine. ${ }^{71}$ Department of Methodology and Statistics, University of Utrecht, Utrecht, the Netherlands. ${ }^{72}$ Department of Epidemiology, Erasmus MC, University Medical Center Rotterdam, Rotterdam, the Netherlands.

\section{Received: 24 April 2018 Accepted: 10 October 2018}

\section{Published online: 05 November 2018}

\section{References}

1. Institute of Medicine (US) and National Research Council (US) Committee to Reexamine IOM Pregnancy Weight Guidelines. In: Rasmussen KM, Yaktine AL, editors. Weight gain during pregnancy: Reexamining the Guidelines. Washington, DC: National Academies Press (US); 2009.

2. Bodnar LM, Hutcheon JA, Parisi SM, Pugh SJ, Abrams B. Comparison of gestational weight gain z-scores and traditional weight gain measures in relation to perinatal outcomes. Paediatr Perinat Epidemiol. 2015;29:11-21.

3. Ludwig DS, Currie J. The association between pregnancy weight gain and birthweight: a within-family comparison. Lancet. 2010;376:984-90.

4. Gaillard R, Durmus B, Hofman A, Mackenbach JP, Steegers EA, Jaddoe WW. Risk factors and outcomes of maternal obesity and excessive weight gain during pregnancy. Obesity (Silver Spring). 2013;21:1046-55.

5. Goldstein RF, Abell SK, Ranasinha S, Misso M, Boyle JA, Black MH, et al. Association of gestational weight gain with maternal and infant outcomes: a systematic review and meta-analysis. JAMA. 2017;317:2207-25.

6. Ohadike CO, Cheikh-Ismail L, Ohuma EO, Giuliani F, Bishop D, Kac G, et al. Systematic review of the methodological quality of studies aimed at creating gestational weight gain charts. Adv Nutr. 2016;7:313-22.

7. Cheikh Ismail L, Bishop DC, Pang R, Ohuma EO, Kac G, Abrams B, et al. Gestational weight gain standards based on women enrolled in the fetal growth longitudinal study of the INTERGROWTH-21st project: a prospective longitudinal cohort study. BMJ. 2016;352:1555.

8. Hutcheon JA, Platt RW, Abrams B, Himes KP, Simhan HN, Bodnar LM. Pregnancy weight gain charts for obese and overweight women. Obesity (Silver Spring). 2015;23:532-5.

9. Johansson K, Hutcheon JA, Stephansson O, Cnattingius S. Pregnancy weight gain by gestational age and BMI in Sweden: a population-based cohort study. Am J Clin Nutr. 2016;103:1278-84.

10. World Health Organization. Global Database on Body Mass Index: BMI Classification. http://www.assessmentpsychology.com/icbmi.htm. Accessed 19 Aug 2015.

11. Yorkin M, Spaccarotella K, Martin-Biggers J, Quick V, Byrd-Bredbenner C. Accuracy and consistency of weights provided by home bathroom scales. BMC Public Health. 2013;13:1194.

12. Rigby RA, Stasinopoulos DM. Generalized additive models for location, scale and shape. Appl Statist. 2005;54:507-54

13. Borghi E, de Onis M, Garza C, Van den Broeck J, Frongillo EA, Grummer-Strawn L, et al. Construction of the World Health Organization child growth standards: selection of methods for attained growth curves. Stat Med. 2006;25:247-65.

14. Rigby RA, Stasinopoulos DM. Using the Box-Cox $t$ distribution in GAMLSS to model skewness and kurtosis. Stat Modelling. 2006;6:209-29. 
15. van Buuren S, Fredriks M. Worm plot: a simple diagnostic device for modelling growth reference curves. Stat Med. 2001;20:1259-77.

16. Royston P, Wright EM. Goodness-of-fit statistics for age-specific reference intervals. Stat Med. 2000;19:2943-62.

17. Pitkin RM. Nutritional support in obstetrics and gynecology. Clin Obstet Gynecol. 1976;19:489-513.

18. Abrams B, Carmichael S, Selvin S. Factors associated with the pattern of maternal weight gain during pregnancy. Obstet Gynecol. 1995;86:170-6.

19. Calvo EB, Lopez LB, Balmaceda Ydel V, Poy MS, Gonzalez C, Quintana L, et al. Reference charts for weight gain and body mass index during pregnancy obtained from a healthy cohort. J Matern Fetal Neonatal Med. 2009;22:3642.

20. Carmichael S, Abrams B, Selvin S. The pattern of maternal weight gain in women with good pregnancy outcomes. Am J Public Health. 1997:87:1984-8.

21. Dawes MG, Grudzinskas JG. Patterns of maternal weight gain in pregnancy. Br J Obstet Gynaecol. 1991;98:195-201.

22. Guelinckx I, Beckers K, Vansant G, Devlieger R. Construction of weight gain charts in a low-risk obstetric Belgian population. Gynecol Obstet Investig 2010;69:57-61.

23. Hutcheon JA, Platt RW, Abrams B, Himes KP, Simhan HN, Bodnar LM. A weight-gain-for-gestational-age $\mathrm{z}$ score chart for the assessment of maternal weight gain in pregnancy. Am J Clin Nutr. 2013:97:1062-7.

24. Ochsenbein-Kolble N, Roos M, Gasser T, Zimmermann R. Cross-sectional study of weight gain and increase in BMl throughout pregnancy. Eur J Obstet Gynecol Reprod Biol. 2007;130:180-6.

25. Rosso P. A new chart to monitor weight gain during pregnancy. Am J Clin Nutr. 1985;41:644-52.

26. Straube $\mathrm{S}$, Voigt $\mathrm{M}$, Briese $\mathrm{V}$, Schneider $\mathrm{KT}$, Voigt $\mathrm{M}$. Weight gain in pregnancy according to maternal height and weight. J Perinat Med. 2008; 36:405-12.

27. Theron GB, Thompson ML. A centile chart for weight gain in pregnancy for the urban population of the Western cape, South Africa. Int J Gynaecol Obstet. 1990;33:127-33.

28. Wong W, Tang NL, Lau TK, Wong TW. A new recommendation for maternal weight gain in Chinese women. J Am Diet Assoc. 2000;100:791-6.

29. Xu J, Luntamo M, Kulmala T, Ashorn P, Cheung YB. A longitudinal study of weight gain in pregnancy in Malawi: unconditional and conditional standards. Am J Clin Nutr. 2014;99:296-301.

30. Poissonnet CM, Burdi AR, Bookstein FL. Growth and development of human adipose tissue during early gestation. Early Hum Dev. 1983;8:1-11.

31. Hutcheon JA, Chapinal N, Bodnar LM, Lee L. The INTERGROWTH-21st gestational weight gain standard and interpregnancy weight increase: a population-based study of successive pregnancies. Obesity (Silver Spring). 2017:25:1122-7.

32. Richmond RC, Timpson NJ, Felix JF, Palmer T, Gaillard R, McMahon G, et al. Using genetic variation to explore the causal effect of maternal pregnancy adiposity on future offspring adiposity: a Mendelian randomisation study. PLoS Med. 2017:14:e1002221.

33. International Weight Management in Pregnancy Collaborative Group. Effect of diet and physical activity based interventions in pregnancy on gestational weight gain and pregnancy outcomes: meta-analysis of individual participant data from randomised trials. BMJ. 2017:358:33119.

34. Muktabhant B, Lawrie TA, Lumbiganon P, Laopaiboon M. Diet or exercise, or both, for preventing excessive weight gain in pregnancy. Cochrane Database Syst Rev. 2015:CD007145.

35. Thangaratinam S, Rogozinska E, Jolly K, Glinkowski S, Roseboom T, Tomlinson JW, et al. Effects of interventions in pregnancy on maternal weight and obstetric outcomes: meta-analysis of randomised evidence. BMJ. 2012:344:e2088.

36. Russell A, Gillespie S, Satya S, Gaudet LM. Assessing the accuracy of pregnant women in recalling pre-pregnancy weight and gestational weight gain. J Obstet Gynaecol Can. 2013;35:802-9.

Ready to submit your research? Choose BMC and benefit from:

- fast, convenient online submission

- thorough peer review by experienced researchers in your field

- rapid publication on acceptance

- support for research data, including large and complex data types

- gold Open Access which fosters wider collaboration and increased citations

- maximum visibility for your research: over $100 \mathrm{M}$ website views per year

At $\mathrm{BMC}$, research is always in progress.

Learn more biomedcentral.com/submissions 